\title{
Leucograma e teores plasmáticos de proteínas de fase aguda de eqüinos portadores de abdômen agudo e submetidos à laparotomia
}

\author{
[Leukogram and plasma acute phase protein concentrations in horses with acute abdomen submitted \\ to treatment by laparotomy] \\ J.J. Fagliari ${ }^{1}$, S.L. Silva ${ }^{2}$, P.C. Silva ${ }^{1}$, G.T. Pereira ${ }^{1}$ \\ ${ }^{1}$ Faculdade de Ciências Agrárias e Veterinárias - UNESP \\ Via de Acesso Prof. Paulo Donato Castellane, s/n \\ 14884-900 - Jaboticabal, SP \\ ${ }^{2}$ Universidade Federal do Tocantins - Araguaína, TO
}

\begin{abstract}
RESUMO
Foram examinados 20 eqüinos adultos portadores de abdômen agudo e submetidos à laparotomia. Dez recuperaram-se sem intercorrência pós-operatória $(\mathrm{G} 1)$ e 10 foram a óbito sete a 10 dias após a cirurgia, com sinais de choque séptico (G2). Avaliaram-se temperatura retal, freqüências cardíaca e respiratória, tempo de preenchimento capilar e teores plasmáticos das proteínas de fase aguda - fibrinogênio, ceruloplasmina, proteína C-reativa, antitripsina, haptoglobina e glicoproteína ácida -, antes e até sete dias após a laparotomia. As leucometrias às $72 \mathrm{~h}$ e no sétimo dia pós-operatório dos eqüinos que foram a óbito foram, respectivamente, $34,6 \%$ e $57,1 \%$, mais altas que a dos animais curados. Os maiores valores de proteína de fase aguda ocorreram no sétimo dia após a cirurgia; os percentuais de elevação de fibrinogênio, antitripsina, glicoproteina ácida, proteína C-reativa, ceruloplasmina e haptoglobina de eqüinos do G2 em relação ao G1 foram 46,8\%, 67,9\%, $91,9 \%, 112,2 \%, 126,9 \%$ e $186,2 \%$, respectivamente.
\end{abstract}

Palavras-chave: eqüino, laparotomia, proteinograma plasmático, leucócitos

\begin{abstract}
Twenty adult horses with acute abdomen were examined and submitted to treatment by laparotomy; ten had no postoperative complication (group 1), and ten showed septic shock symptom and died from seven to ten days after surgery (group 2). Body temperature, heart and respiratory rates, filling capillary time, and plasma acute phase protein concentrations - fibrinogen, ceruloplasmin, C-reactive protein, antitrypsin, haptoglobin, and acid glycoprotein - were evaluated before laparotomy and until seven days after surgery. White blood cell counts at $72 \mathrm{~h}$ and seven days after surgery in group 2 animals were, respectively, $34.6 \%$ and $57.1 \%$, and were higher than those measured in group 1 horses. The highest values of acute phase proteins occurred on the seventh day after surgery. The increase percentages of fibrinogen, antitrypsin, acid glycoprotein, C-reactive protein, ceruloplasmin, and haptoglobin plasma concentrations in group 2 animals in comparison to group 1 animals were $46.8 \%, 67.9 \%, 91.9 \%, 112.2 \%, 126.9 \%$, and $186.2 \%$, respectively.
\end{abstract}

Keywords: horse, laparotomy, plasma proteins, leukocytes

\section{INTRODUÇ̃̃̃O}

A síndrome do abdômen agudo (cólica) é uma das principais causas de urgência cirúrgica em eqüinos. Apesar dos avanços nos métodos de diagnóstico, nas técnicas anestésicas e cirúrgicas e na terapia pós-operatória, a taxa de mortalidade permanece elevada. Considera-se que as indigestões favoreçam a transferência de bactérias e toxinas do lúmen intestinal para a corrente sangüínea, contribuindo para a manifestação de sinais sistêmicos, como choque séptico em eqüinos (Weiss et al., 1997).

Os estágios iniciais da reação inflamatória incluem alterações denominadas resposta de fase

Recebido em 15 de maio de 2007

Aceito em 18 de março de 2008

E-mail: fagliari@fcav.unesp.br 
aguda (Gruys et al., 1994). No sítio inflamatório, ocorrem alterações que favorecem a liberação de citocinas, resultando em respostas sistêmicas, como febre, leucocitose e síntese de proteínas de fase aguda (Takiguchi et al., 1990; Godson et al., 1996). Ressalta-se a importância do proteinograma sérico em humanos, no diagnóstico e no monitoramento de várias doenças e na identificação de focos infecciosos decorrentes de procedimentos cirúrgicos (Wicher e Dieppe, 1985).

Como a concentração plasmática das proteínas de fase aguda é diretamente proporcional ao grau de lesão tecidual e/ou de inflamação (Kent, 1992; Cerón et al., 2005), espera-se que animais portadores de complicações pós-operatórias apresentem maior teor protéico (Wicher e Dieppe, 1985; Gruys et al., 1994). O fibrinogênio é a proteína plasmática mais freqüentemente analisada, porém não é a principal proteína de fase aguda dos animais (Godson et al., 1996).

O fracionamento eletroforético é um dos mais confiáveis métodos de identificação de proteínas séricas. As técnicas de eletroforese mais utilizadas em medicina veterinária têm como matrizes fitas de acetato de celulose (Fagliari et al., 1983; Edinger et al., 1992) ou filmes de agarose (Mattews, 1982), as quais apresentam valor limitado porque permitem o fracionamento de apenas cinco a sete grupos de proteínas. Gordon (1995) relatou que a técnica de eletroforese em gel de acrilamida contendo dodecil sulfato de sódio (SDS-PAGE) é relativamente simples e de baixo custo, possibilitando a visualização de concentrações protéicas extremamente baixas e a identificação de 20 a 30 proteínas, necessitando microquantidade de amostra. Com o uso dessa técnica, foi possível identificar 19 frações no proteinograma sérico de eqüinos com laminite (Fagliari et al., 1997) e 18 em soros de bezerros com fotossensibilização hepatógena (Fagliari et al., 2007).

O objetivo do estudo foi verificar possíveis alterações no leucograma e nos teores plasmáticos de proteínas de fase aguda de eqüinos portadores de abdômen agudo submetidos à laparotomia, que sobreviveram ou não.

\section{MATERIAL E MÉTODOS}

Foram examinados 20 eqüinos adultos, de diferentes raças e sexo, os quais constituíram dois grupos experimentais. O grupo 1 foi formado por eqüinos portadores de abdômen agudo, submetidos à laparotomia para correção de torção de cólon maior (três animais), compactação de cólon maior (cinco animais) e encarceramento nefro-esplênico de cólon maior (dois animais), sem intercorrências no pós-operatório. $\mathrm{O}$ grupo 2 foi formado por eqüinos portadores de abdômen agudo, submetidos à laparotomia para correção de torção de cólon maior (quatro animais), compactação de cólon maior (quatro animais) e encarceramento nefroesplênico de cólon maior (dois animais), porém que vieram a óbito sete a 10 dias após a cirurgia, com sinais de choque séptico. Em ambos os grupos, os sintomas de abdômen agudo haviam surgido 12 a 18 horas antes do atendimento.

Ao longo da cirurgia, os animais de ambos os grupos recebiam infusão intravenosa contínua de solução fisiológica. Durante sete dias de pósoperatório, os eqüinos receberam estreptomicina e penicilina, na dose de 22.000UI do antibiótico $/ \mathrm{kg}$ $\mathrm{PC} / 12 \mathrm{~h}$, via intramuscular (IM) e gentamicina, na dose de $6,6 \mathrm{mg} / \mathrm{kg} \mathrm{PC} / 24 \mathrm{~h}$, via IM. Todos os animais foram submetidos ao exame clínico, segundo Speirs (1997), diariamente, às 8 e $17 \mathrm{~h}$. Avaliaram-se: temperatura retal, turgor cutâneo, coloração das membranas mucosas ocular e oral, características das fezes, motilidade intestinal, tempo de preenchimento capilar, qualidade do pulso e freqüências cardíaca e respiratória.

As amostras de sangue foram obtidas mediante punção jugular, em oito momentos imediatamente antes da laparotomia e, diariamente, a partir da cirurgia, até o sétimo dia pós-operatório. Para a elaboração das tabelas, foram utilizados os resultados obtidos em apenas cinco momentos imediatamente antes da laparotomia e 24, 48 e 72 horas e 7 dias após a cirurgia. Para a realização do leucograma, foram utilizadas amostras de sangue colhidas em frascos que continham ácido etilenodiaminotetracético (EDTA). As contagens de leucócitos foram realizadas em hemocitômetro, e os esfregaços sangüíneos foram corados pelo método de Wright (Jain, 1986) e utilizados para a contagem diferencial. A concentração plasmática de proteína total foi determinada por refratometria. Para o fracionamento das proteínas, utilizou-se eletroforese em gel de acrilaminada contendo dodecil sulfato de sódio (SDS-PAGE), conforme técnica descrita por Laemmli (1970). Após o 
fracionamento, o gel foi corado durante $10 \mathrm{~min}$ em solução de azul de coomassie e, em seguida, colocado em solução de ácido acético a 7\% para retirar o excesso de corante, até que as frações protéicas se apresentassem nítidas. As concentrações dessas proteínas foram determinadas em densitômetro computadorizado ${ }^{1}$. Como referência, utilizou-se uma solução marcadora ${ }^{2}$ com pesos moleculares 29.000, 45.000, 66.000, $97.400,116.000$ e 205.000 dáltons $(\mathrm{Da})$, além de proteínas purificadas $^{2} \quad-$ albumina, $\mathrm{IgG}$, haptoglobina, $\alpha_{1}$-antitripsina e transferrina.

Para a análise estatística utilizou-se o SAS (User's..., 1995). O delineamento foi inteiramente ao acaso, com dois grupos submetidos a avaliações em cinco momentos. Quando se constatou significância entre grupos e momentos, aplicou-se o teste Tukey $(\mathrm{P}<0,05)$ para a comparação das médias.

\section{RESULTADOS E DISCUSSÃO}

$\mathrm{Na}$ Tab. 1, são apresentadas as médias e os desvios-padrão das freqüências cardíaca e respiratória, do tempo de preenchimento capilar e da temperatura retal de eqüinos acometidos por abdômen agudo e submetidos à laparotomia, sem intercorrência pós-operatória $(\mathrm{G} 1)$, e de eqüinos com abdômen agudo que foram a óbito sete a 10 dias após a cirurgia (G2), com sinais de choque séptico. Não houve diferença entre os valores obtidos durante os exames clínicos realizados pela manhã e à tarde. Todos os parâmetros estudados nos dois grupos elevaram-se a partir da cirurgia; nos animais que evoluíram para cura, esses valores aumentaram entre 24 e $48 \mathrm{~h}$ após a intervenção cirúrgica e, a partir daí, decresceram; no sétimo dia pós-operatório, notaram-se valores abaixo daqueles constatados antes da cirurgia, indicando que a causa do distúrbio digestivo foi corrigida com sucesso.

Tabela 1. Média e desvio-padrão da freqüência cardíaca (FC), freqüência respiratória (FR), tempo de preenchimento capilar (TPC) e temperatura retal de eqüinos portadores de abdômen agudo submetidos à laparotomia, sem intercorrência pós-operatória (G1), e de eqüinos portadores de abdômen agudo que foram a óbito sete a 10 dias após a cirurgia $(\mathrm{G} 2)$

\begin{tabular}{lccccc}
\multicolumn{2}{c}{ Parâmetro } & $\begin{array}{c}\text { Antes da } \\
\text { laparatomia }\end{array}$ & \multicolumn{4}{c}{ Tempo após realização da laparotomia } \\
\cline { 3 - 6 } FC/min & & $24 \mathrm{~h}$ & $48 \mathrm{~h}$ & $72 \mathrm{~h}$ & 7 dias \\
G1 & $58,1 \pm 3,7 \mathrm{Aa}$ & $67,4 \pm 7,2 \mathrm{Ab}$ & $65,4 \pm 7,7 \mathrm{Ab}$ & $59,2 \pm 6,27 \mathrm{Aa}$ & $50,8 \pm 6,7 \mathrm{Ac}$ \\
G2 & $60,2 \pm 4,4 \mathrm{Aa}$ & $65,2 \pm 8,7 \mathrm{Ab}$ & $68,9 \pm 7,4 \mathrm{Ab}$ & $66,1 \pm 8,97 \mathrm{Ab}$ & $68,7 \pm 9,1 \mathrm{Bb}$ \\
FR/min & & & & & \\
G1 & $28,5 \pm 3,2 \mathrm{Aa}$ & $36,1 \pm 5,1 \mathrm{Ab}$ & $31,5 \pm 4,6 \mathrm{Aab}$ & $25,1 \pm 3,17 \mathrm{Aa}$ & $20,2 \pm 1,9 \mathrm{Ac}$ \\
G2 & $25,4 \pm 3,4 \mathrm{Aa}$ & $33,4 \pm 5,0 \mathrm{Ab}$ & $31,1 \pm 5,1 \mathrm{Ab}$ & $33,2 \pm 4,76 \mathrm{Bb}$ & $27,6 \pm 3,8 \mathrm{Ba}$ \\
TPC/seg & $3,1 \pm 0,27 \mathrm{Aa}$ & $3,3 \pm 0,37 \mathrm{Aa}$ & $3,3 \pm 0,31 \mathrm{Aa}$ & $3,1 \pm 0,30 \mathrm{Aa}$ & $3,0 \pm 0,29 \mathrm{Aa}$ \\
G1 & $3,3 \pm 0,32 \mathrm{Aa}$ & $3,2 \pm 0,45 \mathrm{Aa}$ & $3,4 \pm 0,56 \mathrm{Aa}$ & $3,5 \pm 0,48 \mathrm{Aa}$ & $3,5 \pm 0,41 \mathrm{Ba}$ \\
G2 & & & & & \\
T.retal $\left({ }^{\circ} \mathrm{C}\right)$ & $38,4 \pm 0,45 \mathrm{Aa}$ & $39,2 \pm 0,59 \mathrm{Ab}$ & $40,1 \pm 0,52 \mathrm{Ac}$ & $38,9 \pm 0,44 \mathrm{Aab}$ & $37,9 \pm 0,58 \mathrm{Aa}$ \\
G1 & $37,9 \pm 0,33 \mathrm{Aa}$ & $39,0 \pm 0,49 \mathrm{Ab}$ & $39,8 \pm 0,87 \mathrm{Ab}$ & $40,7 \pm 0,59 \mathrm{Bc}$ & $39,8 \pm 0,61 \mathrm{Bbc}$ \\
G2 & &
\end{tabular}

Letras maiúsculas diferentes indicam diferenças significativas entre grupos pelo teste Tukey $(\mathrm{P}<0,05)$

Letras minúsculas diferentes indicam diferenças significativas entre momentos pelo teste Tukey $(\mathrm{P}<0,05)$.

É provável que os maiores valores verificados para as freqüências cardíaca e respiratória e para a temperatura retal, 48 a $72 \mathrm{~h}$ após a laparotomia, devam-se à maior liberação de mediadores inflamatórios decorrente da cirurgia, como relataram Gruys et al. (1994). Também, a dor deve ter contribuído para a ocorrência de taquicardia e taquipnéia.

O aumento do tempo de preenchimento capilar, em ambos os grupos, reflete o estado de desidratação dos animais. Em comparação com os animais que foram a óbito após a cirurgia,

${ }^{1}$ Shimadzu CS 9301 - Tokio, Japan.

${ }^{2}$ Sigma - Saint Louis, EUA. 
notou-se que a cinética desses parâmetros foi semelhante entre os grupos até $48 \mathrm{~h}$ após a laparotomia; contudo, a partir de $72 \mathrm{~h}$, e principalmente no sétimo dia pós-operatório, constatou-se que esses valores foram maiores nos eqüinos que foram a óbito. Pode-se incriminar como causa do agravamento do quadro clínico a ação de bactérias e endotoxinas presentes em maior quantidade no sangue desses animais, como salientaram Weiss et al. (1997).

As médias e os desvios-padrão do leucograma são apresentados na Tab. 2. Os animais de ambos os grupos manifestaram leucocitose desde a fase pré-cirúrgica; notou-se que a contagem de leucócitos de eqüinos que evoluíram favoravelmente ao tratamento cirúrgico, obtida no sétimo dia pós-operatório, foi menor, à semelhança dos parâmetros clínicos já mencionados, indicando que o controle ou eliminação da causa de abdômen agudo minimizou a leucocitose, em especial as contagens de polimorfonucleares e de bastonetes. Na Tab. 3 mostram-se os percentuais de elevação das contagens de leucócitos dos eqüinos que foram a óbito após a laparotomia, em relação aos demais. As leucometrias desses animais às $72 \mathrm{~h}$ e no sétimo dia pós-operatório foram, respectivamente, $34,6 \%$ e $57,1 \%$, superiores àquelas dos animais curados. Os percentuais de elevação de polimorfonucleares e de bastonetes, nesses dois momentos, foram de $47,1 \%$ e $70,6 \%$ e de $73,8 \%$ e $132,5 \%$, respectivamente.

Durante toda a fase experimental, a proteinemia foi maior em eqüinos que foram a óbito, porém com valor significativamente mais elevado apenas às $72 \mathrm{~h}$ após a laparotomia (Tab. 4). Nos animais curados, a proteinemia foi menor a partir de $72 \mathrm{~h}$ pós-operatório, à semelhança da temperatura retal, freqüências cardíaca e respiratória e tempo de preenchimento capilar.

A análise dos traçados eletroforéticos indica que, no grupo de eqüinos que foram a óbito, a proteína que se elevou mais precocemente foi a haptoglobina, 22,5\%, 24h após a laparotomia (Tab. 5 e Fig. 1). A partir daí, os percentuais de acréscimo das demais proteínas de fase aguda tenderam à elevação, culminando com valores mais altos no sétimo dia pós-operatório. Nesse momento da pesquisa, os percentuais de elevação dos teores plasmáticos de fibrinogênio, antitripsina, glicoproteína ácida, proteína-C reativa, ceruloplasmina e haptoglobina de eqüinos do $\mathrm{G} 2$ foram 46,8\%, 67,9\%, 91,9\%, $112,2 \%, 126,9 \%$ e $186,1 \%$, respectivamente.

Tabela 2. Média e desvio-padrão da contagem de leucócitos (Leuc.), polimorfonucleares (PMN), bastonetes (Bast.), linfócitos (Linf.), monócitos (Mon.) e eosinófilos (Eos.) de eqüinos portadores de abdômen agudo submetidos à laparotomia, sem intercorrência pós-operatória (G1), e de eqüinos portadores de abdômen agudo que foram a óbito sete a 10 dias após a cirurgia (G2)

\begin{tabular}{|c|c|c|c|c|c|}
\hline \multirow[t]{2}{*}{ Parâmetro } & \multirow{2}{*}{$\begin{array}{c}\text { Antes da } \\
\text { laparotomia }\end{array}$} & \multicolumn{4}{|c|}{ Tempo após realização da laparotomia } \\
\hline & & $24 \mathrm{~h}$ & $48 \mathrm{~h}$ & $72 \mathrm{~h}$ & 7 dias \\
\hline \multicolumn{6}{|l|}{ Leuc/ $\mu 1$} \\
\hline G1 & $12.070 \pm 1.910 \mathrm{Aa}$ & $13.040 \pm 1.610 \mathrm{Aab}$ & $14.020 \pm 1.940 \mathrm{Ac}$ & $12.350 \pm 2.070 \mathrm{Aab}$ & $10.040 \pm 1.700 \mathrm{Ad}$ \\
\hline G2 & $13.340 \pm 2.980 \mathrm{Aa}$ & $14.070 \pm 2.270 \mathrm{Aa}$ & $15.760 \pm 2.890 \mathrm{Aab}$ & $16.630 \pm 2.430 \mathrm{Bb}$ & $15.770 \pm 3.050 \mathrm{Bb}$ \\
\hline \multicolumn{6}{|l|}{$\mathrm{PMN} / \mu \mathrm{l}$} \\
\hline G1 & $9.145 \pm 1.168 \mathrm{Aab}$ & $9.600 \pm 778 \mathrm{Aa}$ & $10.022 \pm 1.252 \mathrm{Aa}$ & $8.747 \pm 1.137 \mathrm{Abc}$ & $6.979 \pm 1.190 \mathrm{Ac}$ \\
\hline $\mathrm{G} 2$ & $9.986 \pm 1.321 \mathrm{Aa}$ & $10.424 \pm 1.410 \mathrm{Aab}$ & $11.854 \pm 1.735 \mathrm{Abc}$ & $12.868 \pm 1.895 \mathrm{Bc}$ & $11.904 \pm 1.523 \mathrm{Bbc}$ \\
\hline \multicolumn{6}{|l|}{ Bast $/ \mu 1$} \\
\hline G1 & $312 \pm 157 \mathrm{Aa}$ & $427 \pm 183 \mathrm{Ab}$ & $674 \pm 266 \mathrm{Ac}$ & $290 \pm 190 \mathrm{Aa}$ & $120 \pm 108 \mathrm{Ad}$ \\
\hline G2 & $398 \pm 132 \mathrm{Aa}$ & $597 \pm 190 \mathrm{Ab}$ & $722 \pm 365 \mathrm{Ab}$ & $504 \pm 395 \mathrm{Bb}$ & $279 \pm 267 \mathrm{Ba}$ \\
\hline \multicolumn{6}{|l|}{$\operatorname{Linf} / \mu \mathrm{l}$} \\
\hline G1 & $2.006 \pm 552 \mathrm{Aa}$ & $2.255 \pm 641 \mathrm{Aa}$ & $2.168 \pm 509 \mathrm{Aa}$ & $2.334 \pm 380 \mathrm{Aa}$ & $2.485 \pm 418 \mathrm{Aa}$ \\
\hline G2 & $2.202 \pm 566 \mathrm{Aa}$ & $2.386 \pm 589 \mathrm{Aa}$ & $2.235 \pm 614 \mathrm{Aa}$ & $2.454 \pm 553 \mathrm{Aa}$ & $2.332 \pm 612 \mathrm{Aa}$ \\
\hline \multicolumn{6}{|l|}{ Mon $/ \mu 1$} \\
\hline G1 & $440 \pm 272 \mathrm{Aa}$ & $484 \pm 220 \mathrm{Aa}$ & $638 \pm 267 \mathrm{Aa}$ & $559 \pm 262 \mathrm{Aa}$ & $250 \pm 141 \mathrm{Ab}$ \\
\hline $\mathrm{G} 2$ & $443 \pm 178 \mathrm{Aa}$ & $468 \pm 197 \mathrm{Aa}$ & $567 \pm 231 \mathrm{Aa}$ & $589 \pm 294 \mathrm{Aa}$ & $443 \pm 291 \mathrm{Aa}$ \\
\hline \multicolumn{6}{|l|}{$\operatorname{Eos} / \mu 1$} \\
\hline G1 & $178 \pm 96 \mathrm{Aa}$ & $271 \pm 161 \mathrm{Aa}$ & $317 \pm 197 \mathrm{Aa}$ & $257 \pm 154 \mathrm{Aa}$ & $204 \pm 126 \mathrm{Aa}$ \\
\hline G2 & $201 \pm 104 \mathrm{Aa}$ & $233 \pm 145 \mathrm{Aa}$ & $336 \pm 201 \mathrm{Aa}$ & $247 \pm 211 \mathrm{Aa}$ & $198 \pm 143 \mathrm{Aa}$ \\
\hline
\end{tabular}

Letras maiúsculas diferentes indicam diferenças significativas entre grupos pelo teste Tukey $(\mathrm{P}<0,05)$.

Letras minúsculas diferentes indicam diferenças significativas entre momentos pelo teste Tukey $(\mathrm{P}<0,05)$. 
Tabela 3. Percentuais de elevação das contagens de leucócitos, polimorfonucleares (PMN), bastonetes, linfócitos, monócitos e eosinófilos de eqüinos portadores de abdômen agudo que foram a óbito sete a 10 dias após laparotomia, antes e após a cirurgia, em relação aos valores de eqüinos portadores de abdômen agudo, sem intercorrência pós-operatória

\begin{tabular}{lccccc}
\hline \multirow{2}{*}{ Parâmetro } & $\begin{array}{c}\text { Antes da } \\
\text { laparotomia }\end{array}$ & \multicolumn{4}{c}{ Tempo após realização da laparotomia } \\
\cline { 3 - 6 } Leucócitos & 10,5 & $24 \mathrm{~h}$ & $48 \mathrm{~h}$ & $72 \mathrm{~h}$ & 7 dias \\
PMN & 9,2 & 7,9 & 12,4 & $34,6^{*}$ & $57,1^{*}$ \\
Bastonetes & 27,6 & 8,6 & 18,3 & $47,1^{*}$ & $70,6^{*}$ \\
Linfócitos & 9,8 & 39,8 & 7,1 & $73,8^{*}$ & $132,5^{*}$ \\
Monócitos & 0,7 & 5,8 & 3,1 & 5,1 & $-6,2$ \\
Eosinófilos & 12,9 & $-3,3$ & $-11,1$ & 5,4 & 77,20 \\
& $-14,1$ & 6,0 & $-3,9$ & $-2,9$ \\
\hline
\end{tabular}

*Aumento significativo $(\mathrm{P}<0,05)$.

Tabela 4. Média e desvio-padrão dos teores plasmáticos de proteína total $(\mathrm{g} / \mathrm{dl})$ e de proteínas de fase aguda (mg/dl) identificadas no traçado eletroforético (SDS-PAGE) de eqüinos portadores de abdômen agudo submetidos à laparotomia, sem intercorrência pós-operatória (G1), e de eqüinos portadores de abdômen agudo que foram a óbito sete a 10 dias após a cirurgia (G2)

\begin{tabular}{|c|c|c|c|c|c|}
\hline \multirow{2}{*}{ Proteína, peso molecular e grupo } & \multirow{2}{*}{$\begin{array}{c}\text { Antes da } \\
\text { laparotomia }\end{array}$} & \multicolumn{4}{|c|}{ Tempo após realização da laparotomia } \\
\hline & & $24 \mathrm{~h}$ & $48 \mathrm{~h}$ & $72 \mathrm{~h}$ & 7 dias \\
\hline \multicolumn{6}{|l|}{ Proteína total $(\mathrm{g} / \mathrm{dl})$} \\
\hline G1 & $7,55 \pm 0,51 \mathrm{Aa}$ & $7,97 \pm 0,37 \mathrm{Ab}$ & $7,64 \pm 0,39 \mathrm{Aab}$ & $7,16 \pm 0,39 \mathrm{Ac}$ & $7,06 \pm 0,30 \mathrm{Ac}$ \\
\hline G2 & $7,69 \pm 0,70 \mathrm{Aa}$ & $8,01 \pm 0,53 \mathrm{Aa}$ & $7,92 \pm 0,61 \mathrm{Aa}$ & $8,11 \pm 0,55 \mathrm{Ba}$ & $7,78 \pm 0,79 \mathrm{Aa}$ \\
\hline \multicolumn{6}{|l|}{ Fibrinogênio (340.000; mg/dl) } \\
\hline G1 & $587 \pm 63 \mathrm{Aa}$ & $689 \pm 65 \mathrm{Ab}$ & $648 \pm 60 \mathrm{Ab}$ & $524 \pm 58 \mathrm{Aac}$ & $506 \pm 64 \mathrm{Ac}$ \\
\hline $\mathrm{G} 2$ & $605 \pm 54 \mathrm{Aa}$ & $743 \pm 79 \mathrm{Ab}$ & $786 \pm 89 \mathrm{Bb}$ & $711 \pm 84 \mathrm{Bb}$ & $743 \pm 93 \mathrm{Bb}$ \\
\hline \multicolumn{6}{|l|}{ Ceruloplasmina $(128.000 ; \mathrm{mg} / \mathrm{dl})$} \\
\hline G1 & $54 \pm 9 \mathrm{Aa}$ & $84 \pm 10 \mathrm{Ab}$ & $86 \pm 10 \mathrm{Ab}$ & $66 \pm 9 \mathrm{Ac}$ & $52 \pm 7 \mathrm{Aa}$ \\
\hline $\mathrm{G} 2$ & $58 \pm 7 \mathrm{Aa}$ & $90 \pm 14 \mathrm{Ab}$ & $98 \pm 11 \mathrm{Bbc}$ & $106 \pm 15 \mathrm{Bc}$ & $118 \pm 23 \mathrm{Bc}$ \\
\hline \multicolumn{6}{|l|}{ Proteína C-reativa $(105.000 ; \mathrm{mg} / \mathrm{dl})$} \\
\hline G1 & $53 \pm 9 \mathrm{Aa}$ & $67 \pm 10 \mathrm{Ab}$ & $67 \pm 11 \mathrm{Ab}$ & $52 \pm 6 \mathrm{Aa}$ & $41 \pm 5 \mathrm{Ac}$ \\
\hline $\mathrm{G} 2$ & $60 \pm 8 \mathrm{Aa}$ & $74 \pm 11 \mathrm{Ab}$ & $71 \pm 13 \mathrm{Ab}$ & $78 \pm 15 \mathrm{Bb}$ & $87 \pm 18 \mathrm{Bb}$ \\
\hline \multicolumn{6}{|l|}{ Antitripsina $(61.000 ; \mathrm{mg} / \mathrm{dl})$} \\
\hline G1 & $456 \pm 51 \mathrm{Aa}$ & $484 \pm 53 \mathrm{Aa}$ & $491 \pm 40 \mathrm{Aa}$ & $371 \pm 39 \mathrm{Ab}$ & $349 \pm 38 \mathrm{Ab}$ \\
\hline $\mathrm{G} 2$ & $463 \pm 62 \mathrm{Aa}$ & $498 \pm 66 \mathrm{Aab}$ & $514 \pm 71 \mathrm{Abc}$ & $522 \pm 70 \mathrm{Bbc}$ & $586 \pm 81 \mathrm{Bc}$ \\
\hline \multicolumn{6}{|l|}{ Haptoglobina $(47.000 ; \mathrm{mg} / \mathrm{dl})$} \\
\hline G1 & $185 \pm 23 \mathrm{Aa}$ & $182 \pm 22 \mathrm{Aa}$ & $139 \pm 21 \mathrm{Ab}$ & $111 \pm 12 \mathrm{Ac}$ & $101 \pm 10 \mathrm{Ac}$ \\
\hline $\mathrm{G} 2$ & $207 \pm 41 \mathrm{Aa}$ & $223 \pm 38 \mathrm{Bab}$ & $243 \pm 37 \mathrm{Babc}$ & $254 \pm 43 \mathrm{Bbc}$ & $289 \pm 51 \mathrm{Bc}$ \\
\hline \multicolumn{6}{|l|}{ Glicoproteína ácida $(43.000 ; \mathrm{mg} / \mathrm{dl})$} \\
\hline G1 & $49 \pm 6 \mathrm{Aa}$ & $56 \pm 7 \mathrm{Aab}$ & $45 \pm 6 \mathrm{Aa}$ & $36 \pm 5 \mathrm{Ac}$ & $37 \pm 4 \mathrm{Ac}$ \\
\hline G2 & $54 \pm 8 \mathrm{Aa}$ & $63 \pm 9 \mathrm{Aa}$ & $60 \pm 8 \mathrm{Bab}$ & $65 \pm 10 \mathrm{Bab}$ & $71 \pm 13 \mathrm{Bb}$ \\
\hline
\end{tabular}

Letras maiúsculas diferentes indicam diferenças significativas entre grupos pelo teste Tukey $(\mathrm{P}<0,05)$.

Letras minúsculas diferentes indicam diferenças significativas entre momentos pelo teste Tukey $(\mathrm{P}<0,05)$. 
Tabela 5. Percentuais de elevação dos teores plasmáticos das proteínas de fase aguda (PFA) de eqüinos portadores de abdômen agudo que foram a óbito sete a 10 dias após laparotomia, antes e após a cirurgia, em relação aos valores de eqüinos portadores de abdômen agudo, sem intercorrência pós-operatória

\begin{tabular}{lccccc}
\hline \multirow{2}{*}{ Proteína } & $\begin{array}{c}\text { Antes da } \\
\text { laparotomia }\end{array}$ & \multicolumn{4}{c}{ Tempo após realização da laparotomia } \\
\cline { 3 - 6 } & 1,8 & $24 \mathrm{~h}$ & $48 \mathrm{~h}$ & $72 \mathrm{~h}$ & 7 dias \\
\hline Proteína total & 3,1 & 1,7 & 3,7 & 13,3 & 11,6 \\
\hline Fibrinogênio & 7,4 & 7,9 & $21,3^{*}$ & $35,7^{*}$ & $46,8^{*}$ \\
Ceruloplasmina & 13,2 & 7,2 & $13,9^{*}$ & $60,6^{*}$ & $126,9^{*}$ \\
Proteína C-reativa & 1,5 & 10,5 & 6,0 & $50,0^{*}$ & $112,2^{*}$ \\
Antitripsina & 11,9 & 2,9 & 4,7 & $40,7^{*}$ & $67,9^{*}$ \\
Haptoglobina & 10,2 & $22,5^{*}$ & $74,8^{*}$ & $128,8^{*}$ & $186,2^{*}$ \\
Glicoproteína ácida & 12,5 & $33,3^{*}$ & $80,5^{*}$ & $91,9^{*}$ \\
\hline
\end{tabular}

*Aumento significativo $(\mathrm{P}<0,05)$.

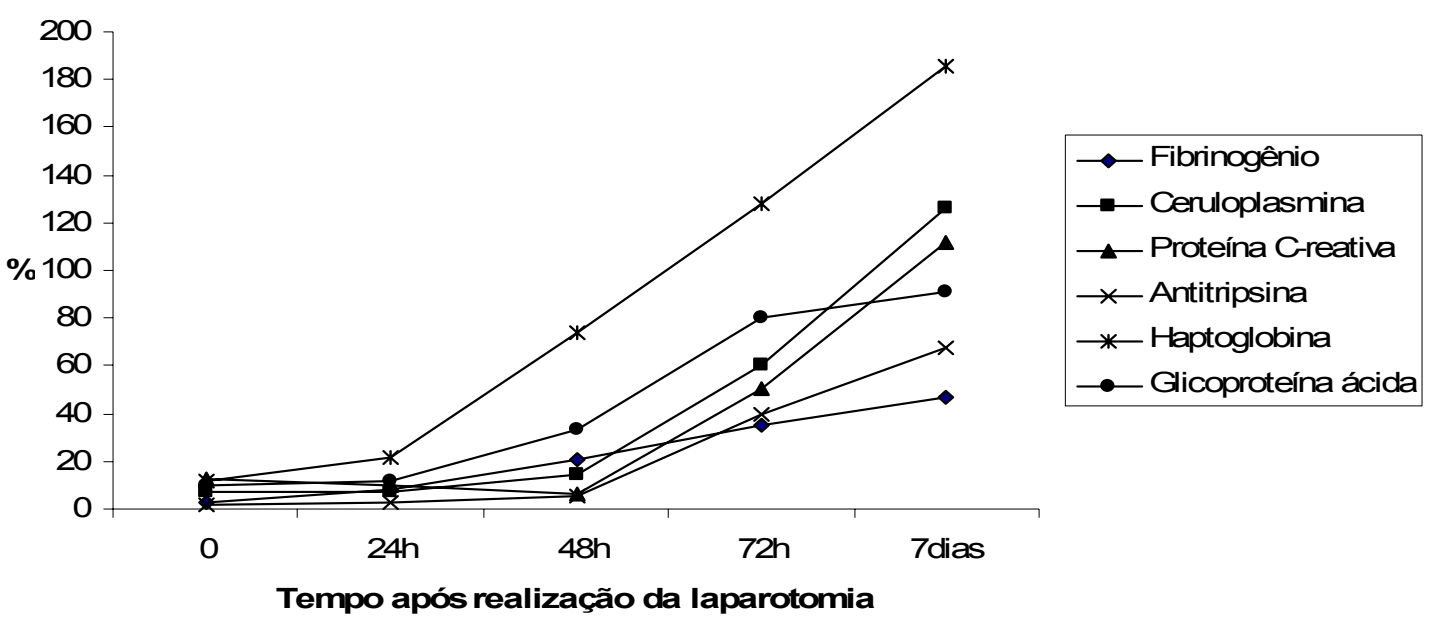

Figura 1. Percentuais de elevação dos teores plasmáticos de fibrinogênio, ceruloplasmina, proteína Creativa, antitripsina, haptoglobina e glicoproteína ácida de eqüinos portadores de abdômen agudo que foram a óbito sete a 10 dias após laparotomia, antes e após a cirurgia, em relação aos valores de eqüinos portadores de abdômen agudo, sem intercorrência pós-operatória.

Em eqüinos do G1, os teores de proteínas do plasma diminuíram a partir de $72 \mathrm{~h}$ após a cirurgia em razão da menor liberação de proteínas de fase aguda, sintetizadas no fígado em resposta às citocinas inflamatórias (Wicher e Dieppe, 1985; Takiguchi et al., 1990; Edinger et al., 1992; Gruys et al., 1994; Godson et al., 1996), e em razão do controle ou da eliminação da causa indutora do quadro clínico de abdômen agudo. Os maiores percentuais de elevação constatados nos eqüinos do G2 deveram-se, possivelmente, aos distúrbios inflamatórios e infecciosos decorrentes do agravamento do quadro clínico, indicando que a concentração plasmática das proteínas de fase aguda é diretamente proporcional ao grau de lesão (Kent, 1992; Cerón et al., 2005).
Pode-se considerar que os resultados do leucograma e do proteinograma correspondem à cinética da resposta leucocitária e da resposta das proteínas de fase aguda de eqüinos portadores de abdômen agudo submetidos à laparotomia.

\section{CONCLUSÕES}

As avaliações da temperatura retal, das freqüências cardíaca e respiratória, do tempo de preenchimento capilar e dos teores plasmáticos das proteínas de fase aguda - fibrinogênio, ceruloplasmina, proteína C-reativa, antitripsina, haptoglobina e glicoproteína ácida possibilitaram prognosticar a evolução do quadro clínico de eqüinos portadores de 
abdômen agudo, submetidos à laparotomia. Dentre os exames laboratoriais considerados indicadores de prognóstico para abdômen agudo de eqüinos, destacaram-se as contagens de polimorfonucleares e bastonetes e, dentre as proteínas de fase aguda, os teores plasmáticos de haptoglobina e ceruloplasmina.

\section{REFERÊNCIAS BIBLIOGRÁFICAS}

CERÓN, J.J.; ECKERSALL, P.D.; MARTÍNEZ-SUBIETA, S. Acute phase proteins in dogs and cats: current knowledge and future perspectives. Vet. Clin. Pathol., v.34, p.85-89, 2005.

EDINGER, V.H.; MILLER, I.; STANEK, C. Electrophoretic serum protein patterns in laminitic horses. Dstch. Tierarztl.Wochenschr., v.99, p.426-430, 1992.

FAGLIARI, J.J.; FERREIRA NETO, J.M.; LUCAS, A. et al. Proteinograma total e fracionamento eletroforético do soro de bezerros Guzerá passivamente imunizados contra paratifo. Arq. Bras. Med. Vet. Zootec.,v.35, p. 317-332, 1983.

FAGLIARI, J.J.; McCLENAHAN, D., EVANSON, O.A. et al.Changes in plasma proteina concentrations in ponies with experimentally induced alimentary laminitis. Am. J. Vet. Res., v.59, p.1234-1237, 1997.

FAGLIARI, J.J.; PASSIPIERI, H.T.; OKUDA, S.L. et al. Serum protein concentrations, including acute phase proteins, in calves with hepatogenous photosensitization. Arq. Bras. Med. Vet. Zootec., v.59, p.1355-1358, 2007.

GODSON. D.L.; CAMPOS, M.; ATTAHPOKU, S.K. Serum haptoglobulin as an indicator of the acute phase response in bovine respiratory disease. Vet. Immunol., v.51, p.277292, 1996.

GORDON, A.H. Electrophoresis of proteins in polyacrylamide and starch gels. New York: Elsever Publisher Company, 1995. 213p.

GRUYS, E.; OBWOLO, M.J.; TOUSSAINT, M.J.M. Diagnostic significance of the major acute phase proteins in veterinary clinical chemistry: a review. Vet. Bull., v.64, p.10091018, 1994.

JAIN, N.C. Schalm's veterinary hematology. 4.ed. Philadelphia: Lea \& Febiger, 1986. 1221p.

KENT, J. Acute phase proteins: their use in veterinary diagnosis. Br. Vet. J.,v.148, p.279282, 1992.

LAEMMLI, U.K. Cleavage of structural proteins during the assembly of the head of bacteriophage $\mathrm{T}_{4}$. Nature, v.227, p.680-685, 1970.

MATTEWS, A.G. Serum protein electrophoresis in horses and ponies. Equine Vet. J., v.14, p.322-324, 1982.

SPEIRS, C.V. Clinical examination of horses. Pennsylvania: Saunders Company, 1997. p.358.

TAKIGUCHI, M.; FUJINAGA, T. ; NAIKI, M. et al. Isolation, characterization, and quantitative analysis of c-reactive protein from horses. Am. J. Vet. Res., v.51, p.1215-1220, 1990.

USER'S guide, version 6.2. Cary: SAS Institute, 1995.

WEISS, D.J.; EVANSON, O.A.; FAGLIARI, J.J. A preliminary study of mucosal barrier function in experimental equine laminitis. Vet. Pathol., v.34, p.480, 1997.

WICHER, J.T.; DIEPPE, P.A. Acute phase proteins. Clin. Immunol. Allergy, v.5, p.425-446, 1985. 